\title{
Research Paper: Study of the Pattern and Frequency of Road Traffic Injuries in Car Occupants in the Eastern Part of Iran
}

\author{
Davood Soroosh $^{1}$, Mohammad Nematshahi ${ }^{2}$, Seyed Alireza Javadinia ${ }^{3 *}$, Mitra Hesamifard $^{4}$
}

1. Department of Internal Medicine, School of Medicine, Sabzevar University of Medical Sciences, Sabzevar, Iran.

2. Department of Anesthesiology, School of Medicine, Sabzevar University of Medical Science, Sabzevar, Iran.

3. Student Research Committee, Mashhad University of Medical Sciences, Mashhad, Iran.

4. Department of Emergency Medicine, School of Medicine, Sabzevar University of Medical Sciences, Sabzevar, Iran.

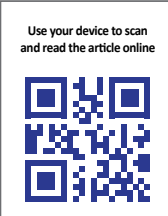

Critation: Soroosh D, Nematshahi M, Javadinia SA, Hesamifard M. Study of the Pattern and Frequency of Road Traffic Injuries in Car Occupants in the Eastern Part of Iran. International Journal of Medical Toxicology and Forensic Medicine. 2020; 10(2):28112. https://doi.org/10.32598/ijmtfm.v10i2.28112

https://doi.org/10.32598/ijmtfm.v10i2.28112

(c) 0

Article info:

Received: 08 Dec 2019

First Revision: 15Dec 2019

Accepted: 18 Jan 2020

Published: 20 Jun 2020

\section{A B STRACT}

Background: Since Iran has one of the highest mortality rates of car accidents in the world, the study of the pattern and reasons of trauma in car occupants can provide useful information to determine the underlying causes of injuries and deaths in traffic accidents. Accordingly, this study was conducted to determine the pattern, frequency, and causes of traumatic injuries caused by traffic accidents in car occupants.

Methods: This cross-sectional study was conducted during the first 6 months of 2017 in Shahid Beheshti Hospital in Sabzevar City, Razavi Khorasan Province, Iran. The data were obtained from the medical records of patients and the checklist designed by our research team.

Results: During the period of study, 300 people were involved in car accidents, of whom $58.3 \%$ were men with an average age of 35.16 years. In both sexes, $29.3 \%$ of the subjects were in the age group of 30-40 years. Twenty-two car occupants were involved in non-injury car accidents. No significant relationship was found between traumatic injuries and variables of sex, seatbelt use, airbag deployment, and the seat occupant in the cars ( $\mathrm{P}>0.05)$, as well as between death and variables of sex, airbag deployment and seat occupant in cars $(\mathrm{P}>0.05)$. But there was a significant relationship between death and fastening seat belts $(\mathrm{P}=0.003)$.

Conclusion: The results of this study revealed that sex, airbag deployment, and seat occupant had no effect on traumatic injury or mortality rate in the car occupants. However, fastening the seatbelt can reduce the mortality rate in car occupants, but it does not impact the traumatic injuries rate.
Injury, Accident, Traffic pattern, Iran
* Corresponding Author:

Seyed Alireza Javadinia, PhD.

Address: Student Research Committee, Mashhad University of Medical Sciences, Mashhad, Iran.

Tel: +98 (51) 44011300

E-mail:javadiniaa941@mums.ac.ir 


\section{Introduction}

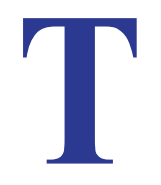

raffic accidents have been a significant public health concern over the last century. According to World Health Organization (WHO) reports, 1.25 million people died of traffic crashes all over the world in 2013, and millions were injured, many of them with several injuries such as physical disabilities for the rest of their lives [1]. Traffic injuries and mortality rates are not equally distributed across different countries of the world. About $85 \%$ of all deaths due to traffic accidents, $96 \%$ of all child deaths for the same reason, and $90 \%$ of loss of lifetime occur in third world countries, while these countries have just $54 \%$ of the world's vehicles [24]. According to WHO reports, road traffic mortality accounts for about $25 \%$ of all deaths [3].

Traffic accidents are the fifth leading cause of disability-adjusted life-years (DALYs) lost, which is expected to reach the third cause in 2030 [5]. Traffic accidents are the leading cause of death between the ages of 15-29 years of life [6]. There is a significant difference in the rate of mortality caused by traffic accidents in different regions of the world. The WHO has reported the rate of road traffic deaths, 26.6 per 100000 population in Africa as the highest, 19.9 in the Eastern Mediterranean countries, 15.9 in the US region, and 9.3 in the European area as the lowest in 2010 [7].

In Iran, too many people are injured or killed every year due to road traffic crashes; most of these accidents can be prevented [8]. The rate of road traffic deaths in Iran in 2004 and 2010 has been reported 38 and 31 per 100000 , respectively. In 2005, Iran, with 37 road traffic accident deaths per 100000 population, had the highest rate of traffic deaths all over the world [9]. Traffic accident injuries with an annual incidence of 26.5 per 100000 population are the second cause of death, and the leading cause of potential life lost due to premature deaths (the years of life lost or YLL), in Iran [10].

On the other hand, many improvements have been made in the management of traumatic injuries resulting from traffic accidents. However, these injuries are of the main causes of death in people affected by traffic accidents. Among them, brain injury is the most common cause of death, accounting for a quarter to one-third of the deaths caused by these accidents [11]. Accordingly, since Iran has one of the highest rates of death resulting from traffic accidents in the world, examining the pattern and causes of traumas in car occupants can provide useful information to reduce the related injuries and fatalities.
The identification of more frequent or severe traumatic injuries can help identify the seat with a higher risk in a car to determine the priority of handling the injured occupants and providing appropriate medical treatment. So, this study was conducted to determine the pattern, frequency, and causes of traumatic injuries resulting from traffic accidents in car occupants in Sabzevar City, Iran, in 2017.

\section{Materials and Methods}

This cross-sectional study was conducted during the first 6 months of 2017 in Shahid Beheshti Hospital of Sabzevar. This hospital is affiliated with Sabzevar University of Medical Sciences and Health Services and is the only trauma center in this city. It also provides 24hour services. All traffic injured occupants who were referred to Shahid Beheshti Hospital during the study period were included in the study, and the required data were extracted from their medical records. Patients whose information was not available or incomplete were excluded. The admitted patients to the emergency department were assessed based on a checklist designed by the researcher. This checklist contained the following information: type of traumatic injury, gender, age, seat occupant, vehicle type, the existence of an airbag system and crash type (collision with another vehicle, car flipping over, or collisions with other objects).

In this research, the quantitative variables were presented with Mean $\pm \mathrm{SD}$ and the qualitative variables with frequency (percentage). The Chi-square test and $t$ test were used to compare the categorized and quantitative variables, respectively. Logistic regression analysis was performed to assess the relationship between traumatic lesions and some of the predictor variables. The data were analyzed in SPSS V. 16. P-values equal to or less than 0.05 were considered statistically significant.

\section{Results}

During the study period, 300 people had car accidents, of whom $58.3 \%$ were men with an average age of 35.16 years. In both sexes, $29.3 \%$ of the subjects were in the 30 40 years age range. About $41.3 \%$ of injured car occupants were drivers. Also, $58.3 \%$ of people had fastened their seatbelts, and only $28.0 \%$ of airbags worked well. Of those who were traumatized, 9.3\% died. Lower and upper limb injuries accounted for $47.3 \%$ of all traumatic injuries. Twenty-two car occupants were involved in a noninjury car accident. Table 1 presents the demographic and clinical features of patients in road traffic accidents. 
Table 1. Demographic, clinical, and injury-related characteristics of samples

\begin{tabular}{|c|c|c|}
\hline Parameter & Variables & No. (\%) \\
\hline \multirow{3}{*}{ Gender } & Male & $177(59.0)$ \\
\hline & & \\
\hline & Female & $123(41.0)$ \\
\hline \multirow{7}{*}{ Age (y) } & $<20$ & $49(16.3)$ \\
\hline & $20-30$ & $66(22.0)$ \\
\hline & $30-40$ & $88(29.3)$ \\
\hline & & \\
\hline & $40-50$ & 37 (12.4) \\
\hline & $50-60$ & $47(15.7)$ \\
\hline & $>60$ & $13(4.3)$ \\
\hline \multirow{3}{*}{ Seatbelt } & Yes & $175(58.3)$ \\
\hline & & \\
\hline & No & $125(41.7)$ \\
\hline \multirow{3}{*}{ Airbag } & Yes & $84(28.0)$ \\
\hline & & 210 \\
\hline & No & $213(72.0)$ \\
\hline \multirow{3}{*}{ Patient setting } & Driver & $124(41.3)$ \\
\hline & Front seat passenger & $87(29.0)$ \\
\hline & Rear seat passenger & $89(27.6)$ \\
\hline \multirow{3}{*}{ Death } & Yes & $28(9.3)$ \\
\hline & & \\
\hline & No & $272(90.7)$ \\
\hline \multirow{4}{*}{ accidents } & Head and neck & $13(4.3)$ \\
\hline & Trunk & $123(41.0)$ \\
\hline & Lower and Upper limp & $142(47.3)$ \\
\hline & Non-injury accidents & $22(7.3)$ \\
\hline
\end{tabular}

Among non-injured occupants, 14 and 8 cases were male and female, respectively, who referred to the hospital. The results of the statistical analysis showed no significant relationship between sex and traumatic lesions $(\mathrm{P}=0.64)$. Also, 15 out of the 175 people who worn seatbelts had traumatic lesions. There was no statistically significant relationship between wearing seatbelt and traffic injuries $(\mathrm{P}=0.33)$. Of 84 cases in which the airbag operated, 6 had injuries, and no significant association was found between the operation of the airbag and the trauma. Also, in terms of seat occupants, 10, 7, and 5 injured people were drivers, front, and rear seat passengers, respectively, and no significant relationship was found between the seat occupant and the trauma $(\mathrm{P}=0.87)$ (Table 2).
Regarding the people who died, 18 and 10 were male and female, respectively. No significant relationship between sex and death was detected $(\mathrm{P}=0.55)$. Nine and 19 people who died were restrained and non-restrained with seatbelts, respectively. The results of the statistical analysis showed a significant relationship between wearing seatbelt and death $(\mathrm{P}=0.003)$. Of the people who died, 3 were with deployed airbags and 25 without using airbag, respectively. There was no significant relationship between the airbag deployment and death $(\mathrm{P}=0.08)$. Of the people who died, 13, 11, and 4 were respectively drivers, front, and rear seat passengers. However, no significant statistical relationship was found between the vehicle seat occupant and death $(\mathrm{P}=0.33)$ (Table 3$)$. 
Table 2. Factors associated with injury in samples (Univariate analysis)

\begin{tabular}{|c|c|c|c|c|}
\hline Parameter & Category & $\begin{array}{l}\text { Non-injury } \\
\text { Accidents }\end{array}$ & Injury Accidents & $\mathbf{P}$ \\
\hline \multirow{3}{*}{ Gender } & Male & 14 & 163 & \multirow{3}{*}{0.64} \\
\hline & & & & \\
\hline & Female & 8 & 115 & \\
\hline \multirow{3}{*}{ Seatbelt } & Yes & 15 & 160 & \multirow{3}{*}{0.33} \\
\hline & & & & \\
\hline & No & 7 & 118 & \\
\hline \multirow{3}{*}{ Airbag } & Yes & 6 & 78 & \multirow{3}{*}{0.82} \\
\hline & & & & \\
\hline & No & 16 & 197 & \\
\hline \multirow{3}{*}{ Patient setting } & Driver & 10 & 114 & \multirow{3}{*}{0.87} \\
\hline & Front seat passenger & 7 & 80 & \\
\hline & Rear seat passenger & 5 & 84 & \\
\hline
\end{tabular}

Also, based on the results of logistic regression analysis, none of the four independent variables (gender, seat belt use, airbag deployment, and seat occupant) entered the regression model, had any effect on the occurrence of a traumatic event $(\mathrm{P}>0.05)$ (Table 4$)$.

\section{Discussion}

This study aims to determine the pattern and frequency of traumatic injuries in seat occupants caused by traffic accidents in Sabzevar City in 2017. The results of this study, which was conducted on 300 car occupants, showed no significant relationships between traumatic injuries with variables of sex, seatbelt wearing, airbag deployment, and seat occupant in cars. Also, there was no significant relationship between death with variables of sex, airbag operation, and the seat occupant in a car. The only significant association was between death and seatbelt use.

Based on the findings of the present study, traumatic injuries in men were more than women, although this difference was not statistically significant. The results are consistent with other studies [12-15] because men are more likely to work outside and, therefore, more at risk of accidents.

Table 3. Factors associated with death in samples (Univariate analysis)

\begin{tabular}{|c|c|c|c|c|}
\hline Parameter & Category & Death & No Death & $\mathbf{P}$ \\
\hline \multirow{3}{*}{ Gender } & Male & 18 & 159 & \\
\hline & & & & 0.551 \\
\hline & Female & 10 & 113 & \\
\hline \multirow{3}{*}{ Seatbelt } & Yes & 9 & 166 & \\
\hline & & & & 0.003 \\
\hline & No & 19 & 106 & \\
\hline \multirow{3}{*}{ Airbag } & Yes & 3 & 81 & \\
\hline & & & & 0.081 \\
\hline & No & 25 & 188 & \\
\hline \multirow{3}{*}{ Patient setting } & Driver & 13 & 111 & \\
\hline & Front seat passenger & 11 & 76 & 0.334 \\
\hline & Rear seat passenger & 4 & 55 & \\
\hline
\end{tabular}


Table 4. Multivariable logistic regression analysis to identify variables associated with traumatic brain injury in restrained drivers involved in road traffic accidents

\begin{tabular}{cccc}
\hline Parameter & Odds Ratio & Confidence Interval & $P$ \\
\hline Gender & 1.13 & $(0.45,2.88)$ & 0.79 \\
Seatbelt & 1.39 & $(0.47,4.09)$ & 0.54 \\
Airbag & 1.10 & $(0.69,1.74)$ & 0.67 \\
\hline Patient setting & 1.09 & $(0.67,1.74)$ & 0.72 \\
\hline
\end{tabular}

The results of our study also showed that in both sexes, the age group of 30-40 years had the highest rate of traumatic injuries, which are consistent with the findings of the other studies [16-18]. This finding could be attributed to the more engagement of this group in social and occupational activities than others.

In this study, injuries were found to be most commonly occurred to the lower and upper limb, followed by trunk, head, and neck. The higher rate of lower and upper limb lesions in this study are consistent with the results of studies conducted by Ganveer in 2005 and Pathak in 2014, both in India $[19,20]$. These cases may be caused by the interaction of gravity force and speed of the vehicle at the time of the collision [21]. But Mishra in Nepal and Jha in India reported a higher rate of injuries in head, neck, and trunk [14]. An explanation for this inconsistency could be that most occupants in the present study used seatbelts, which prevents hitting head and neck to the front of the car.

The findings of this study suggest an inverse relationship between seatbelt use and death in car occupants. The same result has also been reported by many earlier studies [22-24]. It has been demonstrated that fastening the seatbelt would reduce $40 \%$ to $50 \%$ of death cases in front seat occupants as well as $25 \%$ in rear occupants [25]. Even though using seatbelt reduced traumatic injuries in this study, the reduction was not statistically significant.

The results indicate no significant relationship between the operation of the airbag with death and traumatic injuries in car occupants. But the results of previous studies suggest that the deployment of airbag prevents death and reduces the incidence of serious traumatic injuries in non-lethal crashes [26-28]. However, in some studies, increased facial fractures, ocular injuries, and spinal column and neck injuries have been reported as damages secondary to the airbag deployment [29-31].
In this study, no significant relationship was found between the seat occupant in the car and death. Our findings do not match the earlier studies that claimed that people sitting in the rear seat of vehicles were less likely to die than front-seat occupants [32-34].

The main study limitation is the sample who were confined to the people referred to the hospital. So, the people who died at the scene of the accident or those who did not refer to the hospital were not included in the study. Other limitations include conducting interviews with people in the hospital environment and losing some needed information, such as fastening seatbelts. Also, some people refused to participate in the study, resulting in a small sample size.

\section{Conclusion}

The results of this study showed that sex, airbag deployment, and the seat occupant in the car had no significant relationship with the injury or death of the occupants. Still, seatbelt use could reduce the rate of death of car occupants.

\section{Ethical Considerations}

\section{Compliance with ethical guidelines}

Sabzevar University of Medical Sciences approved the study protocol.

\section{Funding}

Sabzevar University of Medical Sciences supported this article.

\section{Author's contributions}

Designed: Davood Soroosh; All authors contributed in preparing this article. 


\section{Conflict of interest}

The authors declared no conflict of interest.

\section{Acknowledgments}

Athors would like to acknowledge the staff of Shahid Beheshti Hospital in Sabzevar City, Iran, for cooperation in collecting the information of the study patients.

\section{References}

[1] Hyder AA, Paichadze N, Toroyan T, Peden MM. Monitoring the decade of action for global road safety 2011-2020: An update. Glob Public Health. 2017; 12(12):1492-505. [DOI:10.10 80/17441692.2016.1169306] [PMID]

[2] Toroyan T. Global status report on road safety. Inj Prev. 2009; 15(4):286. [DOI:10.1136/ip.2009.023697] [PMID]

[3] Krug EG, Sharma GK, Lozano R. The global burden of injuries. Am J Public Health. 2000; 90(4):523-6. [DOI:10.2105/ AJPH.90.4.523] [PMID] [PMCID]

[4] Bhat MA, Sandhu SS, Singh P. Fatal road traffic accidents: A study of autopsied cases. J Medico-Legal Update. 2018; 18(2):90-3. [DOI:10.5958/0974-1283.2018.00135.4]

[5] Bazargan-Hejazi S, Ahmadi A, Shirazi A, Ainy E, Djalalinia $\mathrm{S}$, Fereshtehnejad S-M, et al. The burden of road traffic injuries in Iran and 15 surrounding countries: 1990-2016. Arch Iran Med. 2018; 21(12):556-65. https://www.ncbi.nlm.nih. gov/pubmed/30634852

[6] Nantulya V, Reich MR. The neglected epidemic: Road traffic injuries in developing countries. BMJ. 2002; 11(324):1139-41. [DOI:10.1136/bmj.324.7346.1139] [PMID] [PMCID]

[7] Wismans J, Skogsmo I, Nilsson-Ehle A, Lie A, Thynell M, Lindberg G. Commentary: Status of road safety in Asia Traffic Inj Prev. 2016; 17(3):217-25. [DOI:10.1080/15389588. 2015.1066498] [PMID]

[8] Mansoori F, Khoshnood A, Lesaan H, Najafi M. Knowledge, attitude and practice of out-of-town drivers, on initial medical efforts for the victims of road traffic crashes. Saf Promot In Prev. 2018; 6(1):25-30. http://journals.sbmu.ac.ir/en-spip/ article/view/22158

[9] Sadeghi-Bazargani H, Samadirad B, Moslemi F. A decade of road traffic fatalities among the elderly in north-West Iran BMC Public Health. 2018; 18(1):111. [DOI:10.1186/s12889017-4976-2] [PMID] [PMCID]

[10] Khosravi A, Aghamohamadi S, Kazemi E, Pour Malek F, Shariati M. Mortality profile in Iran (29 provinces) over the years 2006 to 2010. Tehran: Ministry of Health and Medical Education; 2013. https://scholar.google.com/ scholar?hl=en\&as_sdt $=0,5 \&$ cluster $=8872389082514416164$

[11] Jennett B. Epidemiology of head injury. Arch Dis Child. 1998; 78(5):403-6. [DOI:10.1136/adc.78.5.403] [PMID] [PMCID]
[12] Santamariña-Rubio E, Pérez K, Olabarria M, Novoa AM Gender differences in road traffic injury rate using time travelled as a measure of exposure. Accid Anal Prev. 2014; 1(65):17. [DOI:10.1016/j.aap.2013.11.015] [PMID]

[13] Farooqui JM, Chavan KD, Bangal RS, Syed MM, Thacker PJ, Alam S, et al. Pattern of injury in fatal road traffic accidents in a rural area of western Maharashtra, India. Australas Med J. 2013; 6(9):476-82. [DOI:10.21767/AMJ.2013.1839] [PMID] [PMCID]

[14] Mishra B, Sinha Mishra ND, Sukhla S, Sinha A. Epidemiological study of road traffic accident cases from Western Nepal. Indian J Community Med. 2010; 35(1):115-21. [DOI:10.4103/0970-0218.62568] [PMID] [PMCID]

[15] Gómez-Talegón MT, Alvarez FJ. Road traffic accidents among alcohol-dependent patients: The effect of treatment. Accid Anal Prev. 2006; 38(1):201-7. [DOI:10.1016/j. aap.2005.09.006] [PMID]

[16] Mitra S, Sarkar AP, Saren AB, Haldar D, Saha I, Sarkar GN Road traffic injuries: A study on severity and outcome among inpatients of a tertiary care level hospital of West Bengal, India. J Emerg Trauma Shock. 2018; 11(4):247-52. [DOI:10.4103/ JETS.JETS_138_17] [PMID] [PMCID]

[17] Menon A, Pai VK, Rajeev A. Pattern of fatal head injuries due to vehicular accidents in Mangalore. J Forensic Leg Med. 2008; 15(2):75-7. [DOI:10.1016/j.jflm.2007.06.001] [PMID]

[18] Montazeri A. Road-traffic-related mortality in Iran: A descriptive study. Public Health. 2004; 118(2):110-3. [DOI:10.1016/S0033-3506(03)00173-2]

[19] Ganveer GB, Tiwari RR. Injury pattern among non-fatal road traffic accident cases: A cross-sectional study in Central India. Indian J Med Sci. 2005; 59(1):9-12. [DOI:10.4103/00195359.13812] [PMID]

[20] Pathak SM, Jindal AK, Verma AK, Mahen A. An epidemiological study of road traffic accident cases admitted in a tertiary care hospital. Med J Armed Forces India. 2014; 70(1):32 5. [DOI:10.1016/j.mjafi.2013.04.012] [PMID] [PMCID]

[21] Mehta SP. An epidemiological study of road traffic accident cases admitted in Safdarjang Hospital, New Delhi. Indian J Med Res. 1968; 56(4):456-66. https://www.ncbi.nlm. nih.gov/pubmed/5687703

[22] Evans L. The effectiveness of safety belts in preventing fatalities. Accid Anal Prev. 1986; 18(3):229-41. [DOI:10.1016/00014575(86)90007-2

[23] MacKenzie EJ, Siegel JH, Shapiro S, Moody M, Smith RT. Functional recovery and medical costs of trauma: An analysis by type and severity of injury. J Trauma. 1988; 28(3):281-97. [DOI:10.1097/00005373-198803000-00003] [PMID]

[24] Mohammadi M, Ansari Moghaddam A, Rad M, Hashemi Habybabady R, Tabasi MA. Seatbelt use and related factors among drivers involved in road crashes in southeast Iran. Health Scope. 2015; 4(4):e30782. [DOI:10.17795/jhealthscope-30782

[25] Elvik R, Vaa T. The handbook of road safety measures Amesterdam: Elsevier; 2004. https://www.amazon.com/ Handbook-Road-Safety-Measures/dp/0080440916

[26] Mohan D. Traffic Safety. BMJ. 2005; 10(330):367. [DOI:10.1136/bmj.330.7487.367] [PMCID] 
[27] Murphy RX, Jr., Birmingham KL, Okunski WJ, Wasser $\mathrm{T}$. The influence of airbag and restraining devices on the patterns of facial trauma in motor vehicle collisions. Plast Reconstr Surg. 2000; 105(2):516-20. [DOI:10.1097/00006534200002000-00005] [PMID]

[28] McIntosh SE, Brant-Zawadzki G, Milliner BH, Christensen ED, Nyberg AA, Grissom CK, et al. Cause of death in utah avalanche fatalities, 2006-2007 through 2017-2018 winter seasons. Wilderness Environ Med. 2019; 30(2):191-194 [DOI:10.1016/j.wem.2019.02.007] [PMID]

[29] Blacksin MF. Patterns of fracture after air bag deployment. J Trauma. 1993; 35(6):840-3. [DOI:10.1097/00005373199312000-00006] [PMID]

[30] Brookes CN. Maxillofacial and ocular injuries in motor vehicle crashes. Ann R Coll Surg Engl. 2004; 86(3):149-55. [DOI:1 0.1308/003588404323043247] [PMID] [PMCID]

[31] Roccia F, Servadio F, Gerbino G. Maxillofacial fractures following airbag deployment. J Craniomaxillofac Surg. 1999; 27(6):335-8. [DOI:10.1054/jcms.1999.0082] [PMID]

[32] Evans L, Frick MC. Seating position in cars and fatality risk. Am J Public Health. 1988; 78(11):1456-8. [DOI:10.2105/ AJPH.78.11.1456] [PMID] [PMCID]

[33] Huelke DF, Compton CP. The effects of seat belts on injury severity of front and rear seat occupants in the same frontal crash. Accid Anal Prev. 1995; 27(6):835-8. [DOI:10.1016/00014575(95)00021-6]

[34] Smith KM, Cummings P. Passenger seating position and the risk of passenger death or injury in traffic crashes. Accid Anal Prev. 2004; 36(2):257-60. [DOI:10.1016/S0001-4575(03)00002-2] 
This Page Intentionally Left Blank 